\title{
Psychological Well Being and Self Esteem among Children (18-25 Years) of Mentally Ill Parents at a Selected Psychiatric Unit, Mangaluru - A Correlational Study
}

\author{
Nimisha Roy ${ }^{1}$, Thereza Mathias ${ }^{2}$ \\ ${ }^{1}$ Student MSc.(N), Department of Psychiatric Nursing, Laxmi Memorial College of Nursing, Mangaluru-575002, Karnataka, India \\ ${ }^{2}$ Professor\& Head of Department, Department of Psychiatric Nursing, Laxmi Memorial College of Nursing, Mangaluru-575002, \\ Karnataka, India
}

\begin{abstract}
Introduction: A Large number of children grow up with a parent who has a mental health problem. Parents and children or young people often feel isolated and unsupported when the parent is unwell, which can increase distress and anxiety across the family. Aims and Objectives: To assess the psychological well being among children of mentally ill parents, to determine the self esteem among children of mentally ill parents, to find the correlation between psychological well being and self esteem among children of mentally ill parents, to find the association of psychological well being and self esteem among children of mentally ill parents with selected demographic variables. Study design: descriptive corelational study design. Methods and materials: study was conducted among 100 children (18-25years) of mentally ill parents by using purposive sampling technique. A survey approach was used in the study. Tools used for the study were Demographic Proforma, Psychological well being scale by Bhogle and Jaiprakash and Rosenberg's self esteem scale. Results: Majority, (55\%) of the samples found to be having intermediate psychological well-being. $45 \%$ of the samples were having high psychological well-being. None of the samples had poor psychological well being. Highest percentage (91\%) of subjects had normal level of self-esteem and $6 \%$ had low self-esteem and 3\% had high self-esteem. There is no significant correlation between the level of Psychological well-being and self esteem scores among children of mentally ill parents. There is a significant association between psychological well being scores and gender $(p<0.034)$. However the psychological well-being scores with other variables showed no significance at 0.05 levels.
\end{abstract}

Keywords: Psychological well-being, self esteem, mentally ill parents, correlational study

\section{Introduction}

Mental illness is a condition that impairs a person's thinking, feeling or mood and may affect his or her ability to relate to others and function on a daily basis. It can be very mild such as mild depression when things look much worse than they are or very severe for example when a person's life is totally dominated by an illness such as schizophrenia, and they cannot live independently. ${ }^{[1]}$

It is estimated that mental illness will affect 1 in 4 of us at some time in our lives. When a person is mentally healthy, they feel good about themselves. They can do their daily routine easily like going to school or work, and enjoying their hobbies and friends. Even when things go wrong, they can usually sort it out themselves, although this may not be easy. When someone becomes mentally ill, they may find daily routine very difficult to do and they may feel confused and upset after. They may do things that seem normal to them, but to other people watching they may seem strange. ${ }^{[2]}$

Patients suffering from psychosis are unable to distinguish the real from unreal. They experience hallucinations and delusions that they believe are real, and they typically behave in an inappropriate and confused manner. Maternal and paternal mental illness can affect the children in several areas of life. They tend to have social deficits characterized by emotional instability, aggressiveness, and social isolation, difficulties in work, marriage, and struggle with issues related to poor self esteem, and social adjustment. They undergo negative experiences in their childhood such as childhood abuse, neglect, isolation and guilt. ${ }^{[3]}$

Mental illness can compromise a parent's ability to care for children and the manner in which a parent interacts with his or her children. for example, fathers with depression spend less time with their children than fathers without depression. ${ }^{[4]}$ There is also evidence that anxious parents are less likely to grant their children autonomy and more likely to demonstrate lower levels of sensitivity ${ }^{[5]}$ All the children of a parent with a mental illness may experience a home environment different from many other children. A study summarized this environment "children whose parents are mentally ill live with the symptoms, behaviors and expressions of mental illness, they see it and feel it", ${ }^{\text {,[6] }}$

Many children will grow up with a parent who, at some point, will have some degree of mental illness. Most of these parents will have mild or short lived illnesses, and will usually be treated by their general practitioner. A few children live with a parent who has a severe mental illness such as schizophrenia or bipolar disorder. In fact $68 \%$ of women and $57 \%$ of men with a mental illness are parents. In addition many children live with a parent who has long term mental health problems, as well as alcohol or drug problems and personality disorders. ${ }^{[7]}$ 


\section{International Journal of Science and Research (IJSR) \\ ISSN (Online): 2319-7064}

Index Copernicus Value (2016): 79.57 | Impact Factor (2015): 6.391

The effect of a parent's mental illness on children is varied and unpredictable. Although parental mental illness poses biological, psychosocial and environmental risks for children, not all children will be negatively affected, or affected in the same way. The fact that a parent has mental illness alone is not sufficient to cause problems for the child and family. Rather, it is how the mental health condition affects the parent's behavior as well as familial relationships that may cause risk to a child. The age of onset, severity and duration of the parent's mental illness, the degree of stress in the family resulting from the illness, and most importantly, the extent to which parents' symptoms interfere with positive parenting, such as their ability to show interest in their children, will determine the level of risk to a child. The child's age and stage of development is also important. ${ }^{[8]}$

Children of parents with a mental illness are at high risk of developing psychological problems themselves at some point in their lives. Studies showed that as many as $50 \%$ of children with a mentally ill parent are at risk of developing problems. ${ }^{[9]}$ For instance, these children can become socially isolated because they have to care for their mentally ill parent instead of spending time with friends or playing sports. ${ }^{[10]}$ Children with a mentally ill parent may more frequently experience negative emotions, including anger, fear, and sadness. Hence, they are at elevated risk for both internalizing and externalizing problems. These internalizing and externalizing problems in childhood have in turn been found to predict later disorders, such as mood and anxiety disorders and antisocial personality disorder. ${ }^{[1]}$

Parents are typically the most proximal and influential people in a child's development, particularly during the early years. Parental mental illness can significantly impact family life. There can be confusion in family roles, with children assuming many adult responsibilities For instance, children may be responsible for caring for younger brothers and sisters or managing household duties; they may even have the responsibility of taking care of the emotional or physical needs of their parents. ${ }^{[12]}$

Psychological well-being is said to be the fundamental of mental health. According to the World Health Organization 2011, mental health is defined as a "state of wellbeing in which every individual realizes his or her own potential, can cope with the normal stresses of life, can work productively and fruitfully, and is able to make a contribution to his or her community." Traditionally it is said to be the absence of distressful symptoms and includes more positive qualities. ${ }^{[13]}$

Self-esteem is how a person feels about themselves and what they do. Someone with positive self-esteem will generally approach things thinking they are good who deserve love and support and can succeed in life. Someone with low or negative self-esteem will generally think they are not good at things, don't deserve love or support and that situation will work out badly for them. ${ }^{[14]}$

Mental health stigma affects people with mental illness because society labels and judges them negatively. This is often the case for parents with mental illness who are often told that they are inadequate caregivers, simply because they have mental health challenges. They are accused of not being able to properly care for their children, especially their own and at times they are left battling for their right to be a parent. But parents with mental illnesses deserve more than mental health stigma. ${ }^{[15]}$

\section{Literature Survey}

Children of mentally ill parents - A pilot study of a group intervention program were conducted in 2015. In a quasi experimental design three groups are compared: An intervention group (family talk intervention group: $n=28$ ), a wait control group $(n=9)$, and a control group of healthy children $(n=40)$. Mean age of children was 10.41 years and parental disorders were mostly depressive/ affective disorders $(n=30)$, but a small number also presented with attention deficit hyperactivity disorder $(n=7)$. Results show that children of mentally ill parents have higher rates of internalizing/ externalizing disorders before and after the intervention compared to children of parents with no disorders. Post intervention children's knowledge on mental disorders was significantly enhanced in the family talk intervention group compared to wait control group and the healthy control group. ${ }^{[16]}$

Growing up with a parent having Schizophrenia: Experience and Resilience in the offspring was conducted among 45 adults with one parent diagnosed with schizophrenia was selected using purposive sampling. Results showed that the experience perceived by the children of mentally ill parents as different from children of healthy parents. It included negative experience in social $(49 \%)$, and emotional aspects $(40 \%)$ lack of support from the parent who is ill (40\%) and burden $(66 \%)$ in various areas. Majority of the offsprings were satisfied with the parenting received (70\%) about $60 \%$ of them reported medium resilience, and $24 \%$ and $15 \%$ reported high and low resilience respectively. Majority of those with medium and high resilience had supportive relationship with other family members. Social support was most frequently reported factor that helped them to cope up with difficulties. ${ }^{[17]}$

A case control study was conducted in 2008 in Lahore to assess the psychological problems in children of parents with mental illness. Seventy six parents were recruited through interview technique to get a sample of 200 children (100 cases, 100 controls). The results showed that mean age of children was 9.7 years and $55.5 \%$ were boys. Children of parents with psychiatric problems had almost two times higher rate of mental health problems compared to controls (55\% versus $28 \%$; p value $<0.001)$, emotional difficulties $(\mathrm{p}=0.028)$ and conduct problems $(\mathrm{p}=0.025)$ were found to be statistically significant Boys were more likely to be hyperactive and have conduct and social difficulties. Girls had higher rate of emotional problems. ${ }^{[18]}$

Experience of stigma and psychological well being among adult children of parents with schizophrenia was conducted at NIMHANS Bangalore. The study adopted a two group comparison cross sectional methodology. The study group comprised of 30 adult children of parents with schizophrenia and control group consisted of 30 individuals without the history of any mental illness in the parent. The tools used were Socio-demographic data sheet (SDS), the stigma items

\section{Volume 6 Issue 12, December 2017}




\section{International Journal of Science and Research (IJSR) \\ ISSN (Online): 2319-7064}

Index Copernicus Value (2016): 79.57 | Impact Factor (2015): 6.391

of Explanatory Model Interview Catalogue (EMIC) and Psychological Well Being Scale (PWB). Results show that more than $50 \%$ of the participants in the study group experience stigma. Perceived stigma was positively correlated with current psychopathology of the parents. Active psycho-pathology in parents turned out to be a significant predictor of the stigma. The control group had better psychological well-being compared to the study group. ${ }^{[19]}$

A Descriptive correlation study to assess the psychological well being and self esteem among adult children of mentally ill parents was conducted in Karnataka 63 adult children of mentally ill parents were selected by convenient sampling technique. The study findings revealed that $55.6 \%$ of the children had high psychological well being, $42.9 \%$ of the sample had intermediate psychological well being and only $1.6 \%$ had low psychological well being. Majority of the adult children had normal $(68.3 \%)$ self esteem, $30.2 \%$ of the sample had low self esteem, $1.6 \%$ participants had high self esteem. There was no significant correlation $(r=0.444)$ between psychological well being and self esteem. ${ }^{[20]}$

\section{Methods/Approach}

A descriptive corelational study design was adopted and study was conducted among 100 children (18-25 years) of mentally ill parents. Ethical clearance was obtained from Institutional Ethics Committee. The study was conducted at Manaswini clinic Mngaluru. After obtaining the administrative permission, the researcher approached the study subjects, explained the purpose of the study and obtained the consent after assuring them the confidentiality of the data. Participants were children between the age group 18-25 years and had at least one parent diagnosed with schizophrenia, mania, depression, bipolar affective disorder or organic mental disorder, as per the ICD-10 criteria, for more than 1 year. Children who have mental illness were excluded in the study. Children were selected through purposive sampling technique from the OPD and wards of selected psychiatric unit Mangaluru.

Data was collected using Demographic proforma, Psychological well being scale (PWB), by Bhogle and Jaiprakash and Rosenberg's self esteem scale. The tools were translated in to local language Kannada. Psychological well being scale consist of 28 item questionnaire in a forced choice (yes/no) format. In the tool 10 statements $(4,5,6,10$, $12,14,15,16,21$ and 24) are negative and rest 18 statements are positive. Scores are classified (0-9) as low psychological well being, (10-20) as intermediate psychological well being and (21-28) as high psychological well being. Higher the score, higher the psychological well being. The reliability obtained is 0.84. Rosenberg self esteem scale is a structured rating scale to assess the self esteem of general population which was initially developed for adolescence but commonly used for all age groups. The scale consist of 10 items each item was scored on a four point rating scale under the options: strongly agree, agree, disagree, and strongly disagree. Items 3,5,8,9 and 10 were negative questions with reverse scoring. The maximum and minimum scores were thirty and zero respectively. The scores were classified in to three categories: scores between 0 to 14 represents low self esteem, 15 to 25 normal self esteem and above 25 high self esteem. The reliability of the instrument ranges from 0.81 .

\section{Results}

Table 1: Frequency and percentage distribution of children of mentally ill parents with selected demographic variables, $n=100$

\begin{tabular}{|c|c|c|c|}
\hline $\begin{array}{l}\text { Sl. } \\
\text { No }\end{array}$ & Demographic variables & $\begin{array}{l}\text { Frequency } \\
(f)\end{array}$ & $\begin{array}{c}\text { Percentage } \\
(\%)\end{array}$ \\
\hline \multirow[t]{3}{*}{1.} & Age of the child in year & & \\
\hline & a. $18-21$ & 57 & 57.0 \\
\hline & b. $22-25$ & 43 & 43.0 \\
\hline \multirow[t]{3}{*}{2.} & Gender & & \\
\hline & a. Male & 45 & 45.0 \\
\hline & b. Female & 55 & 55.0 \\
\hline \multirow[t]{4}{*}{3.} & Type of family & & \\
\hline & a. Nuclear & 63 & 63.0 \\
\hline & b. Joint & 36 & 36.0 \\
\hline & c. Extended & 01 & 01 \\
\hline \multirow[t]{5}{*}{4.} & Ordinal position in the family & & \\
\hline & a. Only child & 12 & 12.0 \\
\hline & b. First child & 30 & 30.0 \\
\hline & c. Second child & 32 & 32.0 \\
\hline & d. Third and more & 26 & 26.0 \\
\hline \multirow[t]{5}{*}{5.} & Religion & & \\
\hline & a. Hindu & 51 & 51.0 \\
\hline & b. Muslim & 37 & 37.0 \\
\hline & c. Christian & 12 & 12.0 \\
\hline & d. Any other & & \\
\hline \multirow[t]{5}{*}{6.} & Education & & \\
\hline & a. Up to $8^{\text {th }}$ standard & 01 & 1.0 \\
\hline & b. Up to $10^{\text {th }}$ standard & 09 & 9.0 \\
\hline & c. PUC & 48 & 48.0 \\
\hline & d. Degree & 40 & 40.0 \\
\hline \multirow[t]{3}{*}{7.} & $\begin{array}{l}\text { e. Post Graduate } \\
\text { Working Status of children }\end{array}$ & 02 & 2.0 \\
\hline & a. Yes & 29 & 29.0 \\
\hline & b. No & 71 & 71.0 \\
\hline \multirow[t]{3}{*}{8.} & Marital status & & \\
\hline & a. Yes & - & - \\
\hline & b. No & 100 & 100.0 \\
\hline \multirow[t]{4}{*}{9.} & $\begin{array}{l}\text { Duration of illness of the } \\
\text { parents (in years) }\end{array}$ & & \\
\hline & a. $1-5$ & 50 & 50.0 \\
\hline & b. $6-10$ & 30 & 30.0 \\
\hline & c. $>10$ & 20 & 20.0 \\
\hline \multirow[t]{3}{*}{10.} & Place of stay of Parent & & \\
\hline & a. Yes & 100 & 100.0 \\
\hline & b. No & - & - \\
\hline
\end{tabular}

Highest percentage $(57 \%)$ of children of mentally ill is in the age group of $18-21$ years whereas $43 \%$ are in the group 22 25 years. Almost equal $(55 \%)$ of children of mentally ill are females whereas $(45 \%)$ are males. Highest $(63 \%)$ of children belong to nuclear family. Majority $(32 \%)$ of children is second born. Highest percentage $(51 \%)$ of children belongs to Hindu religion. The highest percentage $(48 \%)$ of children has education till PUC. The highest percentage (71\%) children are not working. All the samples are unmarried. The highest percentage $(50 \%)$ parents are suffering from mental illness for the past 1-5 years. 


\section{International Journal of Science and Research (IJSR) \\ ISSN (Online): 2319-7064}

Index Copernicus Value (2016): 79.57 | Impact Factor (2015): 6.391

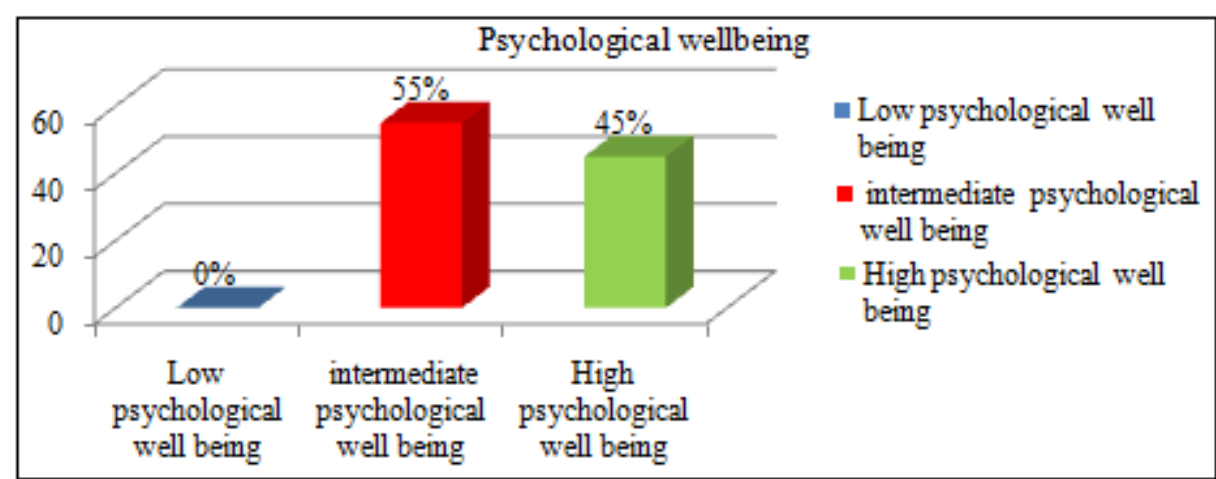

Figure 1: Bar diagram showing level of psychological well-being among children of mentally Ill parents

The data presented in Figure 1 shows that highest percentage $(55 \%)$ of subjects had intermediate psychological well-being and $45 \%$ had high psychological well-being. None of the samples had poor psychological well being.

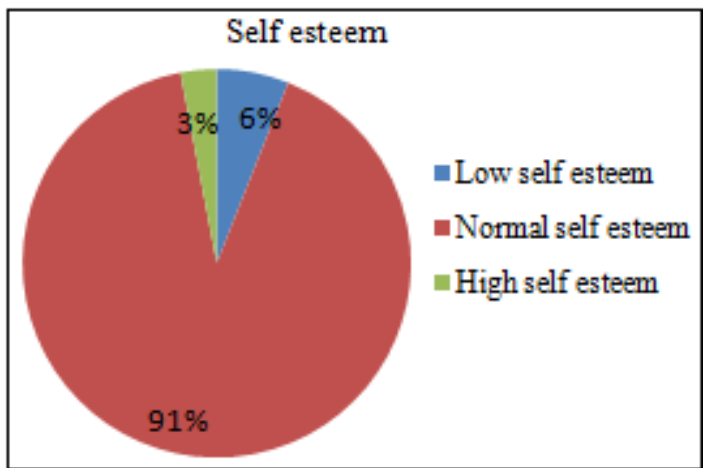

Figure 2: Pie diagram showing the level of self esteem among children of mentally Ill parents.

Data presented in figure 3 shows that highest percentage (91\%) of subjects had normal level of self-esteem and $6 \%$ had low self-esteem and 3\% had high self-esteem.

Table 2: Correlation between psychological well -being and self esteem scores among children of mentally ill parents $\mathrm{n}=100$

\begin{tabular}{|c|c|c|}
\hline Correlation Coefficient & $\mathrm{df}$ & $\mathrm{p}$ value \\
\hline-0.12 & 98 & $\mathrm{p}<0.01$ \\
\hline
\end{tabular}

The data presented in table 2 show that there is no significant correlation between the level of Psychological well-being and self esteem scores among children of mentally ill parents. Thus null hypothesis $\mathrm{H}_{01}$ was accepted that there is no significant association between Psychological well being scores and self esteem scores among children of mentally ill parents.

Table 3: Association of psychological well -being scores among children of mentally ill parents with selected demographic variables, $\mathbf{n}=\mathbf{1 0 0}$

\begin{tabular}{|c|c|c|c|c|c|}
\hline S.N & Demographic variable & $\chi^{2}$ Value & df & p value & Inference \\
\hline 1 & Age & 13.48 & 7 & 0.061 & NS \\
\hline 2 & Gender & 4.50 & 1 & 0.034 & S \\
\hline 3 & Type of family & 1.94 & 2 & 0.379 & NS \\
\hline 4 & Ordinal position & 7.05 & 3 & 0.07 & NS \\
\hline 5 & Religion & 5.24 & 2 & 0.073 & NS \\
\hline 6 & Education & 8.77 & 4 & 0.067 & NS \\
\hline 7 & Working status & 0.00 & 1 & 0.982 & NS \\
\hline 8 & Duration of illness & 4.26 & 2 & 0.119 & NS \\
\hline
\end{tabular}

\section{NS - not significant, S- Significant}

The computed chi-square value shows a significant association between psychological well being scores and gender $(\mathrm{p}<0.034)$. However the psychological well-being scores with other variables like age, type of family, ordinal position in the family, religion, education, working status, marital status, duration of illness of parent, parental stay showed no significance at 0.05 levels. Therefore the null hypothesis $\left(\mathrm{Ho}_{2}\right)$ was rejected for the selected demographic variable gender and the research hypothesis was accepted. Since the computed chi-square value shows no significant association between psychological well being scores and other demographic variables at 0.05 level of significance, the null hypothesis is accepted and research hypothesis was rejected.

Table 4: Association of self esteem scores among children of mentally ill parents with selected demographic variable

\begin{tabular}{|c|c|c|c|c|c|}
\hline S. N & $\begin{array}{c}\text { Demographic } \\
\text { variable }\end{array}$ & $\chi^{2}$ Value & $\mathrm{df}$ & $\mathrm{p}$ value & Inference \\
\hline 1 & Age & 15.57 & 14 & 0.341 & $\mathrm{NS}$ \\
\hline 2 & Gender & 2.617 & 2 & 0.270 & $\mathrm{NS}$ \\
\hline 3 & Type of family & 2.72 & 4 & 0.606 & $\mathrm{NS}$ \\
\hline 4 & Ordinal position & 4.28 & 6 & 0.639 & $\mathrm{NS}$ \\
\hline 5 & Religion & 1.71 & 4 & 0.789 & $\mathrm{NS}$ \\
\hline 6 & Education & 1.48 & 8 & 0.993 & $\mathrm{NS}$ \\
\hline 7 & Working status & 1.514 & 2 & 0.469 & $\mathrm{NS}$ \\
\hline 8 & Duration of illness & 3.57 & 4 & 0.468 & $\mathrm{NS}$ \\
\hline
\end{tabular}

\section{NS - not significant, S- Significant}

The data depicted in table 8 shows that the calculated $\mathrm{p}$ value of demographic variables like age, gender, type of family ordinal position in the family, religion, education, working status, marital status, duration of illness of parent, parental stay is more than the value at 0.05 level of significance. So the investigator accepted the null hypothesis $\left(\mathrm{H}_{03}\right)$. Hence there is no significant association of self esteem scores among children of mentally ill parents with selected demographic variables at 0.05 level of significance

\section{Discussion}

In the present study, out of 100 participants, majority (55\%) of the samples are found to be having intermediate psychological well-being and $45 \%$ of the samples are with high psychological well-being. The mean of the psychological well-being is $19.97 \pm 2.73$. This shows that most of the children of mentally ill parents have intermediate level of psychological well-being. This findings support the

\section{Volume 6 Issue 12, December 2017}




\section{International Journal of Science and Research (IJSR) \\ ISSN (Online): 2319-7064}

Index Copernicus Value (2016): 79.57 | Impact Factor (2015): 6.391

study conducted in Lahore to assess the psychological problems in children of parents with mental illness. The results showed that mean age of children was 9.7 years and $55.5 \%$ were boys. Children of parents with psychiatric problems had almost two times higher rate of mental health problems compared to controls (55\% versus $28 \%$; p value $<0.001)$, emotional difficulties $(\mathrm{p}=0.028)$ and conduct problems $(\mathrm{p}=0.025)$ were found to be statistically significant Boys were more likely to be hyperactive and have conduct and social difficulties. Girls had higher rate of emotional problems. $^{[18]}$

The study also found that out of 100 participants majority $91 \%$ of the samples were found to be having normal self esteem $6 \%$ of the samples were with low self esteem and only $3 \%$ samples having high self esteem. The mean of the self-esteem score among children of mentally ill parents is $20.75 \pm 2.84$. Consistent study findings were reported by a study among adult children showed normal (68.3\%) self esteem, $30.2 \%$ of the sample had low self esteem, $1.6 \%$ participants had high self esteem. ${ }^{[20]}$

In the present study there is no significant relationship between psychological well-being and self esteem among children (18-25yrs) of mentally ill parents $(r=-0.12)$ and it contradicts with a correlative study conducted in Karnataka reports that there was no significant correlation $(r=0.444)$ between psychological well-being and self esteem. ${ }^{[20]}$

The present study revealed that there is a significant association between gender and psychological well-being of children of mentally ill parents. These findings support the study conducted in Thrishnappally, to evaluate the psychological well-being among adolescents in the current scenario. Results indicated that socio-demographic variables do not influence adolescent psychological well-being. Gender and age negatively relate with psychological wellbeing. Stay in hostel is positively related with psychological well-being. ${ }^{[21]}$

There was no significant association between self esteem and selected demographic variables. These findings were supported by a study to examine the relationships among home environment, parent's personality and mental health of adolescents with a focus on adjustment, anxiety, selfconcept and self- confidence. Results indicate that parental care was associated with high self confidence while parental pressure was associated with high anxiety. Disturbed families contributed to adolescent anxiety. Parental traits were found to negatively influence mental health.

\section{Conclusion}

The present study found that majority $(55 \%)$ of the samples were found to be having intermediate psychological wellbeing and $45 \%$ of the samples were with high psychological well-being. About $91 \%$ of the samples found to be having normal self esteem $6 \%$ of the samples were with low self esteem and only $3 \%$ participants having high self esteem. There is no significant relationship between psychological well-being and self esteem among children of mentally ill parents. There is a significant association between psychological well being scores and gender $(p<0.034)$.
However the psychological well-being scores with other variables showed no significance at 0.05 levels. There is no significant association of self esteem scores among children of mentally ill parents with selected demographic variables at 0.05 level of significance.

\section{Recommendations}

- A similar study can be conducted by selection of samples by random sampling method.

- A similar study can be done taking in to consideration all the children of the mentally ill parents.

- A comparative study can be done among the adult children of mentally ill parents of rural and urban areas.

- The study may be replicated using a larger population drawn from different hospitals.

- A correlational study can be conducted to find the relationship between psychological well-being and other variables like quality of life, job satisfaction, and burnout among adult children of mentally ill parents.

- A comparative study can be done among the male and female children of mentally ill parents.

\section{Limitations}

- The sample selected was restricted to only one psychiatric unit

- Only those children visiting the parents or accompanying to the psychiatric units for follow up were included in the study.

\section{Acknowledgement}

We acknowledge all the subjects who participated in the study willingly.

\section{References}

[1] Michael Gopfert, Jeni Webster, Mary V Seeman. 'Parental Psychiatric Disorder' Distressed Parents and Their Families. Archives of Diseases in Childhood. 2004; 76(4): 358-364

[2] Phelan JC, Bromet EJ, Link BG. Psychiatric illness and family stigma.

[3] Schizophr Bull 1998; 7: 192-202

[4] Mayberty D, Ling L, Szakacs E, Reupert A, Children of parent with mental illness: Perspectives on need. Australian e-Journal for the advancement of mental health. Adv Mental Health. 2005; 4 (2): 78-88

[5] Bronte- Tinkew J, Moore KA, Mathews G, Carrano J. Symptom of major depression in a sample of fathers of infants. J Fam Issues. 2007; 28: 61-99

[6] Pape SE, Collins MP. A Systematic literature review of parenting behaviours exhibited by anxious People. European Psychiatry.2004; 26(1): 170-178

[7] Aldridge J, Saul Becker. Children as carers: The impact of parental illness and disability on children's caring roles. Journal of family therapy 199; 21(3): 303-320

[8] Jo Aldridge. The experience of children living with and caring for parents with a mental illness. Journal of General and Family Medicine.2006; 26(2): 79-88

\section{Volume 6 Issue 12, December 2017}




\section{International Journal of Science and Research (IJSR) \\ ISSN (Online): 2319-7064}

Index Copernicus Value (2016): 79.57 | Impact Factor (2015): 6.391

[9] Network practical tools for changing environment Making the Invisible Visible: Parents with Psychiatric Disabilities. National Technical Assistance Centre for State Mental Health Planning. Special Issue Parents with Psychiatric Disabilities. Spring, 2000

[10] Karlin TM, Van Doesum, Floor van Santvoort. Prevention of emotional problems and psychiatric risk in children of parents with mental illness in the Netherlands. Australian e- Journal for the Advancement of Mental Health. 2005; 4 (2): 78-88

[11] Beardslee WR, Versage EM, Gladstone TR. Children of affectively ill parents: a review of the past 10 Years. American Journal of Psychiatry.1998; 154(4): 510-515

[12] Beidel, D. C, Turner S. M. At risk for anxiety: Psychopathology in the offspring of anxious parents. Journal of the American Academy of Child and Adolescent Psychiatry. 1997; 36(7):918-924.

[13] Aadil Jan Shah, Ovais Wadoo, Javed Latoo. Psychological distress in carers of people with mental disorders. British Journal of Medical Practitioner.2010; 3(3): 327-334

[14] Huppert FA, Abbott RA, Ploubidis GB, Richard M. Parental practices predict psychological well-being in midlife: life-course associations among women in the 1946 British birth cohort study. Psycho midlife. 2010; 40(9)0: 1507-1518.

[15] Burnett P, Mc Crinde and Andrea R. A study on the relationship between significant other's positive and negative statements, self talk, and self esteem. Centre for cognitive processes in learning school of learning and development. Child Study Journal.1999; 29(1):3948

[16] Manjula M, Rahuram A. Self concept in adult children of schizophrenic parents: An exploratory study. Int J Soc Psychiatry 2009; 55: 471-79

[17] Hanna Christiansen, Jana Anding, Bastian Schrott, Bernd Rohrle. Children of mentally Ill parents- a pilot study of group intervention program. Child and adolescent social Work journal, 2015, 158(8):14941500

[18] Herbert HS, Manjula M, Philip M. Growing up with a Parent having Schizophrenia: Experience and Resilience in the Offspring's. Indian J Psycho Med.2013, 35(2): $148-53$

[19]Nazish Imran, Ahsan Sattar, Naeem Amjad, Muhammad Riaz Bhatti. Psychological problems in children of parents with mental illness, Pak J Med Sci 2009; 25(6): 895-900

[20] Manjula Munivenkatappa, Ahalya Raguram. Experience of stigma and psychological well being among adult children of parents with schizophrenia. An exploratory study. Int J Soc Psychiatry 2014; 55 (3); 471-79

[21] Jayakrishnan, Shalini \& Savita; A correlative study to assess the psychological wellbeing and self-esteem among adult children of mentally ill parents in Kasturba Hospital, Manipal of Udupi district, Nur.Edu. and Research,

[22] 2015; 3(1): 87-90

[23] Shaji KS, George K, Behavioral symptoms and caregiver burden in dementia. Indian journal of psychiatry.2009: 51(1); 45-49

\section{Author Profile}

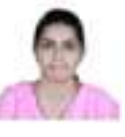

Nimisha Roy did M.Sc Nursing from Laxmi Memorial College of Nursing Mangaluru, Rajiv Gandhi University of Health Sciences in 2017. She did B.Sc Nursing from Jabalpur Institute of Nursing Science and Research Jabalpur, Rani Durgawati Vishwaviddyalya Jabalpur in 2013. She did S.S.L.C and Plus Two from Holy family higher secondary school Rajapuram in 2006 and 2008 respectively. She can speak English, Hindi, Malayalam. She has experience of 1 year at Bombay Hospital as a Clinical Instructor. She has attended many Workshops and Conferences which includes CME on Suicide Prevention on $8^{\text {th }}$ November 2015 organized by the Department of Psychiatry and Indian Psychiatric Society - Karnataka chapter at Yenepoya Medical College. She has Attended CME on DementiaRemember Me and Paranormality on $16^{\text {th }}$ December 2015 organized by the Department of Psychiatry and Indian Psychiatric Society- Karnataka Chapter at A.J Institute of Medical Sciences and Research Centre Mangaluru. Attended one day workshop on Psychological First Aid held at Yenepoya University on $23^{\text {rd }}$ February 207 and a National Conference on Informatics Engaging, Enabling \& Empowering Nurses in Digital Health on $31^{\text {st }}$ July 2017 by department of Nursing Administration. Laxmi Memorial College of Nursing

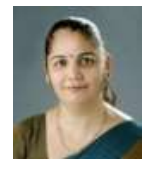

Dr. Thereza Mathias is Professor and HOD at Laxmi Memorial College of Nursing, A.J. Towers, Balmatta, Mangalore-02. In 2015 she did Ph.D in Nursing from Yenepoya University, Mangalore. She did M. Sc. Nursing from Raj Kumari Amrit Kaur College of nursing, New Delhi in 1996 and B. Sc Nursing from Fr. Muller college of nursing, Mangalore in 1992. She can speak English, Konkani, Kannada, Tulu, Hindi, Malayalam. She has completed a certificate course in Biostatistics, Epidemiology and Research Methodology conducted by Department of Statistics, Manipal University from July - December 2010 with 6 credits. She worked as a Lecturer, Associate Professor and Professor in the department of mental health Nursing. Presently working as Professor and HOD department of mental Health Nursing since 10 years in the present institution. I have worked as Senior clinical Instructor at Sultanate of Oman. Latest Publications (2017) includes 1) Cross sectional study on Mobile Phone Usage among Youth .Asian Academic Research Journal of Multidisciplinary. 2017;4(8). 2) Conceptual framework: rings of suicide is accepted for publication in the forth coming issue of Asian Journal of Nursing Education and Research. 3) Effectiveness of planned teaching program on knowledge regarding Alzheimer's disease among the family members of elderly in a selected urban community at Mangalore Indian Journal of Psychiatry. 2016; 58(1), pp44-48. She is Awarded the Best Poster Prize for the poster presented on "Compliance status among mentally ill patients discharged from Psychiatric units in selected community Dakshina Kannada" at the Nitte University's International Symposium on Universal Health coverage in association with Christelijke Mutualiteit, Belgium and India Platform at the $\mathrm{K}$ S Hegde Medical Academy, Nitte University, Mangaluru, India held on 8th April 2017. Awarded the Best Poster on "Adolescent Suicide" at the National conference on "Updates On Managing Psychiatric emergencies" organized by Department of Mental Health Nursing, on 28th february 2017 at Father Muller College of Nursing, Mangaluru. She has attended many seminars and workshop which includes Tridecennial National conference on Edu - Vision2017 creating hash tag in teaching and learning organized by Dr. M.V. Shetty College of Nursing mangalore on $1^{\mathrm{St}}$ September 2017. Attended and was a Judge for the poster competition at the state level workshop on QUALITAS FIDUCIA organized by the department of Administration and II year M.Sc nursing students of Laxmi Memorial College of Nursing, Mangaluru on $28^{\text {th }}$ June 2017 Attended an International Symposium on Universal Health coverage in association with Christelijke Mutualiteit, Belgium and

\section{Volume 6 Issue 12, December 2017}




\section{International Journal of Science and Research (IJSR) \\ ISSN (Online): 2319-7064}

Index Copernicus Value (2016): 79.57 | Impact Factor (2015): 6.391

India Platform at the K S Hegde Medical Academy, Nitte University, Mangaluru, India held on 8th April 2017. Attended a National Conference:PSYCON'2017 on "Updates On Managing Psychiatric emergencies" organized by Department of Mental Health Nursing, on 28th february 2017 at Father Muller College of Nursing, Mangaluru. Attended a workshop YENMIND $-\mathbf{4}$ on Psychological first Aid Organized by department of Psychiatry, Yenepoya Medical College, Yenepoya University Mangaluru on 23 rd February 2017

Volume 6 Issue 12, December 2017

www.ijsr.net 